\title{
Frequency and Characteristics of Ocular Trauma in a Tertiary Care Hospital in Lodhran
}

\author{
Muhammad Luqman Ali Bahoo, Ahmad Zeeshan Jamil, Beenish Karamat
}

Pak J Ophthalmol 2019, Vol. 35, No. 2

See end of article for

authors affiliations

Correspondence to:

Muhammad Luqman Ali Bahoo, MBBS, FCPS, FICO, FACS,

Fellowship Refractive and

Cornea Surgery

Associate Professor and Head

of Ophthalmology, Shahida

Islam Medical and Dental

College, Lodhran.

Email: drluqmanali@yahoo.com ahmadzeeshandr@yahoo.com
Purpose: To find the frequency and characteristics of ocular trauma in a tertiary care hospital in Lodhran.

Study design: Cross sectional study.

Sampling Technique: Convenient non-probability sampling.

Place and duration of study: This study was conducted at Shahida Islam Teaching Hospital affiliated with Shahida Islam Medical College, Lodhran from December 2016 to September 2018.

Material and Methods: Detailed history and ocular examination were performed with regard to age, gender, classification of ocular trauma, aetiology of trauma, place where trauma occurred, note of ocular damage, nature of object, activity at the time of injury, presenting visual acuity and time lapse before presentation to hospital after trauma were recorded.

Results: There were 393 patients included in this study. Mean age of patients was $28.97 \pm 12.59$ years. There were 198 (50.4\%) closed globe and $195(49.6 \%)$ open globe injuries. In $53(13.5 \%)$ cases injury was caused by metal object. In $132(33.6 \%)$ cases injury was classified as contusion. In $146(37.2 \%)$ cases cornea was involved. There were $95(24.2 \%)$ cases that occurred in home. In $156(39.7 \%)$ cases presenting visual acuity was less than 6/60. There were 272 (69.2\%) males and $121(30.8 \%)$ females. There were $342(87.0 \%)$ patients who presented within 1 day after trauma. In $122(31.0 \%)$ cases there was prolapse of ocular contents.

Conclusion: Ocular trauma occurred more commonly in males. It was blunt and occurred in home setting in most of the times. Most of the eye injuries aetiological agent was metal and wood.

Key Words: Blindness. Contusion. Corneal injuries. Ocular trauma.
$\mathrm{E}$ ye trauma is cause of ocular morbidity that can be prevented ${ }^{1}$. It is one of the leading causes of blindness ${ }^{2-4}$. Every year about 1.6 million people become blind due to ocular trauma ${ }^{5}$. Eye injury results in a large number of hospital visits ${ }^{6}$. Ocular trauma results in significant physical, psychological and economical loses ${ }^{7}$. Eye injury results in functional disability, cosmetic blemish, economical loss and psychological distress. Impact of eye injury is long lasting and disturbing for the patient and the whole family. Impact of ocular injury and vision loss is greatest in magnitude compared to the loss of any other sensory organ of the body. Eye injuries can occur in a variety of settings like during playing, in home, at work or as a result of assault or accident ${ }^{8}$. Due to their anatomical location and consistency eyes are prone to get hurt event by trivial trauma. Ocular trauma can be profession specific as persons engaged in certain 
professions are likely to get hurt by certain objects 9 . Every year around 55 million people get injuries in their eyes. One out of every twenty patients coming for eye examination by an ophthalmologist is a sufferer of eye injury ${ }^{10}$. Trauma to eye can lead to immediate damage or it can lead to establishment of inflammation and infection afterwards. Sequel of ocular trauma can cause significant ocular morbidity even after months or years ${ }^{11}$. Self medication by the patients or improper management by the quacks is another contributing factor in morbidity related to ocular trauma. Ocular trauma is often preventable and proper management of ocular injuries can significantly lessen the burden of blindness ${ }^{12}$.

Data about ocular trauma is limited in developing countries in terms of aetiology, setting, extent of injury, pattern of injury and management strategies. As depending on occupation and socio-demographic factors, nature and characteristics of ocular injury differ from region to region, so we want to know the frequency and characteristics of ocular trauma in Lodhran. Good knowledge of aetiology of trauma, patterns and characteristics of trauma and at-risk population is needed to device strategies for prevention and management of this disabling condition. Proper resource allocation for the prevention and treatment of ocular injuries can be planned according to burden of ocular injuries in the region.

\section{MATERIAL AND METHODS}

This cross-sectional study was conducted at Shahida Islam Teaching Hospital affiliated with Shahida Islam Medical College, Lodhran from December 2016 to September 2018. Sample size was calculated according to the following formula:

$\mathrm{S}=\mathrm{Z}^{2} \mathrm{p}(1-\mathrm{p}) / \mathrm{M}^{2}$

$S$ is sample size

$\mathrm{Z}$ is $\mathrm{Z}$ score its value is 1.96

$\mathrm{P}$ is population proportion assumed to be $50 \%$ or 0.5

$\mathrm{M}$ is margin of error that is taken $5 \%$ or 0.05

$\mathrm{S}=(1.96)^{2}(0.5)(1-0.5) / 0.05$

$=384.16$

$=384$

All ocular trauma patients presenting in the out patients department and emergency department who required hospital admission were included in the study. All patients were told about the purpose of the study and informed consent was taken.
Demographic profile like age and gender of all patients were recorded. History regarding aetiology of injury, eye structures involved, place where injury occurred and pattern of injury were recorded.

Ocular injuries were graded according to Birmingham eye trauma terminology into two types namely closed globe and open globe injuries. Closed globe injuries were further divided into contusion and lamellar laceration. Open globe injuries were divided into laceration and rupture. Mechanism of rupture was trauma with blunt object while trauma with sharp object resulted in laceration. Laceration was further divided into penetrating, perforating and presence of intraocular foreign body ${ }^{13}$. Periorbital and adnexa injuries were recorded.

Record was taken of the time elapsed between injury and presentation to hospital. Presenting visual acuity was recorded with Snellen's chart. Detailed ocular examination was performed with the help of slit lamp biomicroscopy. B-scan and X-ray imaging were performed when required.

All the information was gathered with the help of specially designed proforma. Statistical analysis was performed with SPSS version 23. Mean and standard deviation was calculated for age. Frequencies and percentages were calculated for gender, aetiology of injury, type of injury, structures involved, place of injury, presence of hyphema, status of lens, presence of vitreous haemorrhage, status of retina, optic nerve status, presenting visual acuity, time lapse between injury and presentation to hospital and prolapse of intraocular contents.

\section{RESULTS}

There were 393 patients included in this study. There were 272 (69.2\%) males and 121 (30.8\%) females. Mean age of patents was $28.97 \pm 12.59$ years. Distribution of cases according to gender and age is shown in table 1. There were 198 (50.4\%) closed globe injuries and 195 $(49.6 \%)$ open globe injuries. The most common cause of injury was trauma with metal object. The distribution of cases according to trauma is given in table 2.There were 132 (33.6\%) cases of contusion, 99 $(25.2 \%)$ cases of rupture, $66(16.8 \%)$ cases of lamellar laceration, $59(15.0 \%)$ cases of penetration, $27(6.9 \%)$ cases of intraocular foreign bodies and $10(2.5 \%)$ cases of globe perforation. Cornea was involved in 146 (37.2\%) cases, corneoscleral injury was present in 126 $(32.1 \%)$ cases, sclera in $46(11.7 \%)$ cases and adnexa in $27(6.9 \%)$ cases. There was lid tear in $12(3.1 \%)$ cases, 
periocular swelling in $16(4.1 \%)$ cases and blow out fracture was noted in $2(0.5 \%)$ cases. In $18(4.6 \%)$ cases posterior segment was the predominant site of injury. Hyphema was present in $186(47.3 \%)$ cases, lens damage was present in $128(32.6 \%)$ cases, vitreous

Table 1: Distribution of cases according to gender and age.

Age of Patient in years

\begin{tabular}{|llcc|}
\hline $\begin{array}{l}\text { Gender of } \\
\text { Patient }\end{array}$ & $\begin{array}{c}\text { Mean } \\
\text { (Years) }\end{array}$ & $\begin{array}{c}\text { Number of } \\
\text { Cases }\end{array}$ & $\begin{array}{c}\text { Std. } \\
\text { Deviation }\end{array}$ \\
\hline Male & 28.20 & 272 & 14.108 \\
Female & 30.70 & 121 & 8.030 \\
Total & 28.97 & 393 & 12.597 \\
\hline
\end{tabular}

Table 2: Distribution of cases according to aetiology.

\begin{tabular}{|lcc|}
\hline Injury Aetiology & Frequency & Percent \\
\hline Metal & 53 & 13.5 \\
Wood/Vegetable matter & 49 & 12.5 \\
Stone & 26 & 6.6 \\
Road Traffic Accident & 35 & 8.9 \\
Wielding arc & 10 & 2.5 \\
Acid (chemical) & 18 & 4.6 \\
Alkali (chemical) & 18 & 4.6 \\
Superglue (chemical) & 16 & 4.1 \\
Oil & 15 & 3.8 \\
Fist/hand & 19 & 4.8 \\
Fall & 11 & 2.8 \\
Fire work/Fire cracker & 18 & 4.6 \\
Fire & 9 & 2.3 \\
Pellet gun & 27 & 6.9 \\
Plant sap & 7 & 1.8 \\
Insect fall/bite & 14 & 3.6 \\
Animal attack & 11 & 2.8 \\
Glass & 21 & 5.3 \\
Plastic Scale/Pencil/Pen & 12 & 3.1 \\
Tennis Ball & 4 & 1.0 \\
Total & 393 & 100.0 \\
\hline
\end{tabular}

Table 3: Distribution of cases according to place of injury.

\begin{tabular}{|lcc|}
\hline Place of Occurrence & Frequency & Percent \\
\hline Work place & 81 & 20.6 \\
Road traffic accident & 44 & 11.2 \\
Home & 95 & 24.2 \\
Sports & 31 & 7.9 \\
Assault & 58 & 14.8 \\
At school & 24 & 6.1 \\
Outdoor & 60 & 15.3 \\
Total & 393 & 100.0 \\
\hline
\end{tabular}

Table 4: Distribution of cases according to time to presentation in Hospital.

\begin{tabular}{|lcc|}
\hline Time to Presentation & Frequency & Percent \\
\hline Within 1 day & 131 & 86.2 \\
Within 1 week & 17 & 11.2 \\
After 1 week & 4 & 2.6 \\
Total & 152 & 100.0 \\
\hline
\end{tabular}

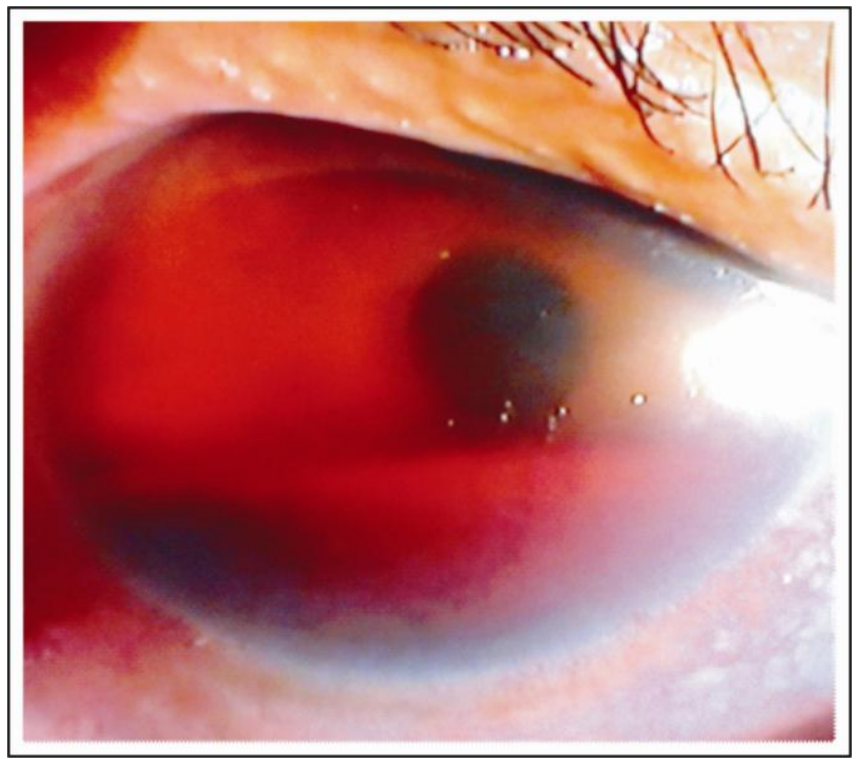

Fig. 1: Hyphema as a result of blunt ocular trauma.

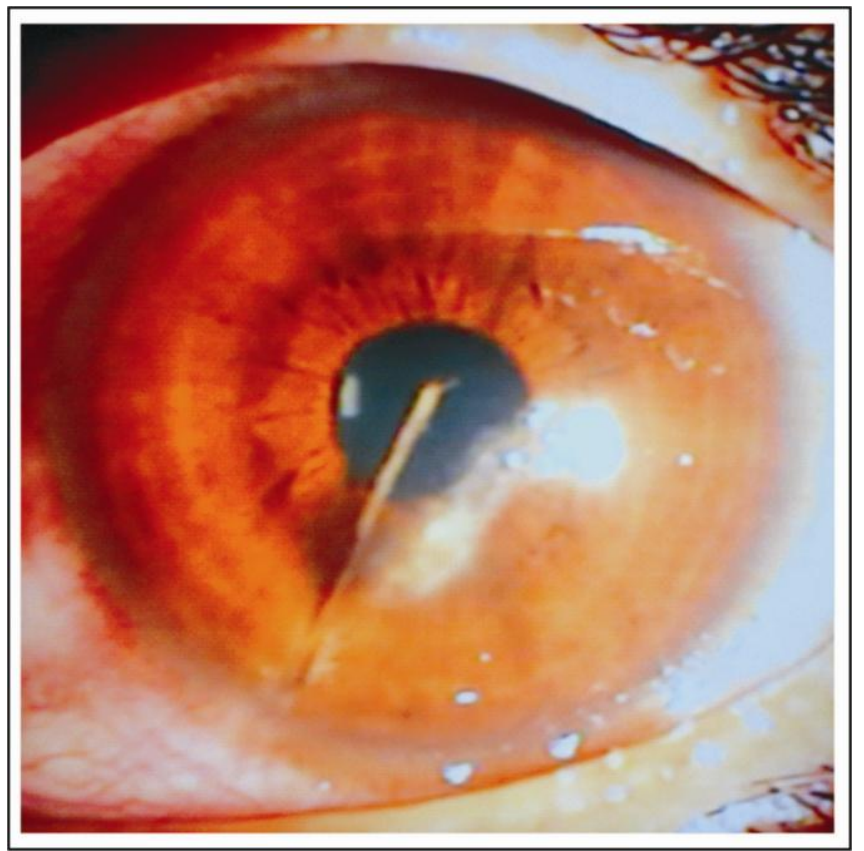

Fig. 2: Ocular penetration with vegetable matter. 
haemorrhage was present in 103 (26.2\%) Cases, retinal tear was present in $13(3.3 \%)$ cases, retinal detachment was present in $29(7.4 \%)$ cases, commotio retina was present in $22(5.6 \%)$ cases. Optic nerve swelling was noted in $32(8.1 \%)$ cases. Distribution of cases according to place of injury is given in table 3 . Presenting visual acuity was $6 / 12$ or better in 139 $(35.4 \%)$ cases, between $6 / 12$ and $6 / 60$ in $98(24.9 \%)$ cases and less than 6/60 in 156 (39.7\%). Distribution of cases according to time to presentation in hospital is shown in table 4 . Prolapse of intraocular contents was noted in $122(31.0 \%)$ cases.

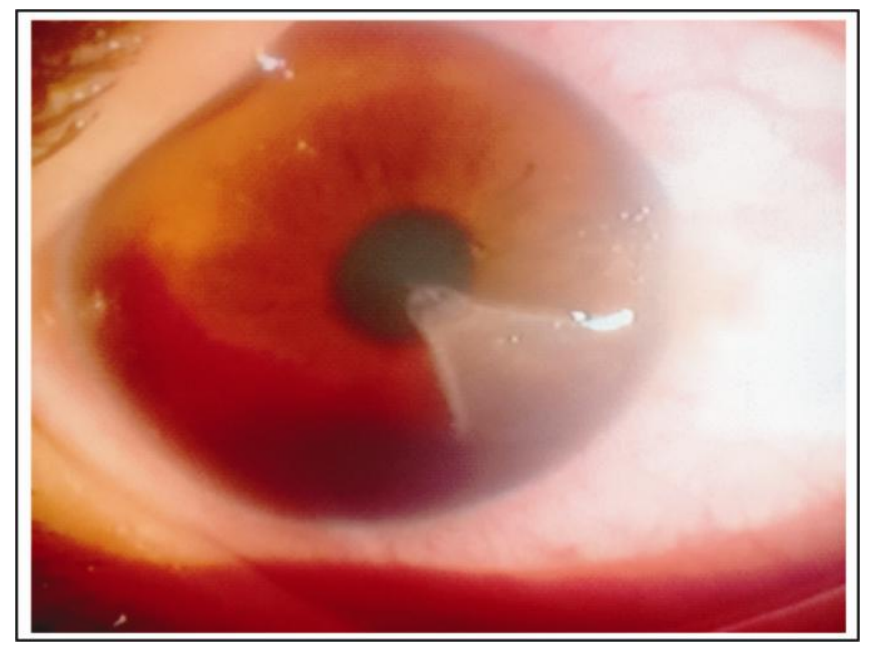

Fig. 3: Lamellar corneal laceration with hyphema.

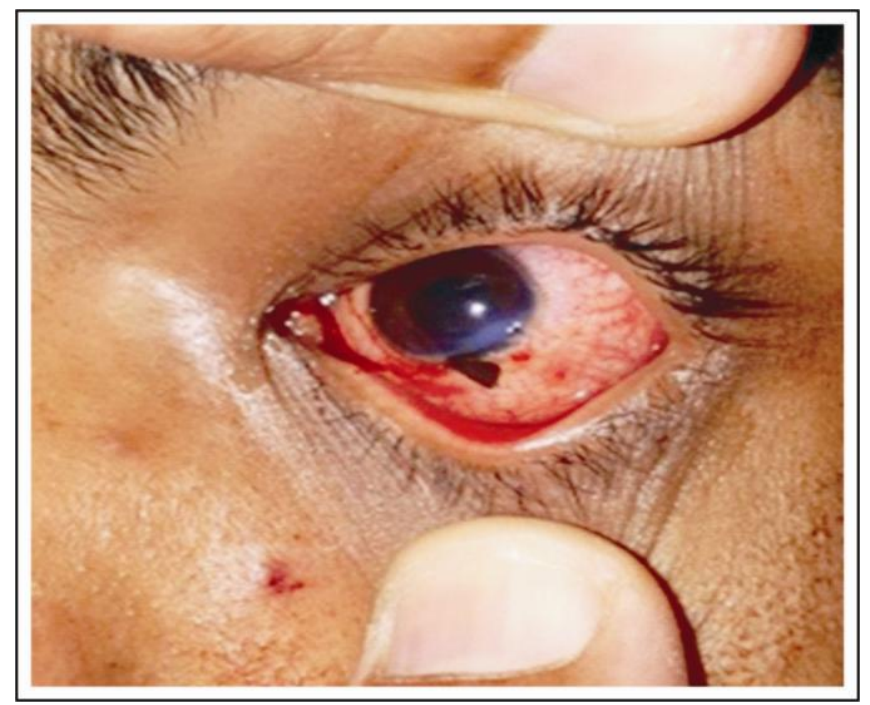

Fig. 4: Limbal perforation, Iris and vitreous prolapsed following ocular trauma with Key.

\section{DISCUSSION}

Ocular trauma is one of the major causes of preventable blindness and visual impairment ${ }^{14}$. Three hundred and ninety-three patients with ocular trauma were included in this study. Mean age of patients was $28.97 \pm 12.59$ years. Results of our study are similar with the findings of study done by Dhulikhel that showed the most vulnerable age group was 21-30 years ${ }^{15}$. Study of Godar and co-authors also recognized the most vulnerable age group for ocular trauma was between 21 to 29 years. Ocular trauma in young age group may be due to their increased risktaking behaviour and active life style. Morbidity resulted thereof has great impact in terms of economical burden and quality of life.

There were $272(69.2 \%)$ males and 121 (30.8\%) females included in our study. Work performed by Sengupta and co-authors also showed the preponderance of male patients affected by ocular trauma ${ }^{16}$. Increase ocular trauma in male patients may be due to their increase outdoor activity and engagement in certain professions ${ }^{17}$.

In our study there were 198 (50.4\%) closed globe injuries and 195 (49.6\%) open globe injuries. Among closed globe injuries, contusion was the most common cause. Among open globe injuries, globe rupture was the most common cause. Our results are similar to findings of other studies. In our study most common cause of injury was metal object and cornea was involved in majority of cases. Our results are in accordance with the result of other studies ${ }^{18}$.

In our study most common place of injury was home. Our results are in contrast with the results of other studies ${ }^{19}$ where most of ocular trauma occurred at work place and during road traffic accidents. Our results are in accord with that of the study conducted by Shaeri and co-authors ${ }^{20}$. Due to inadequate adoption of safety measures during common house hold activities may be reason for majority of ocular trauma at home. Most of the trauma among women and children occur at home. It is irony that home environment that is considered the safest accounted for majority of ocular trauma. Adoption of safety measures at home while doing house hold activities is as much needed as during outdoor activities.

In our study time to presentation to hospital was within one day in $342(87.0 \%)$ cases, within 7 day in 41 $(10.4 \%)$ cases and after 1 week in $10(2.5 \%)$ cases. Our results are comparable to that of Godar and coauthors ${ }^{14}$. 
In our study presenting visual acuity was less than 6/60 in 156 (39.7\%) while in another study conducted by Sengupta and co-authors majority of patients presented with visual acuity less than $3 / 60^{16}$. This is in contrast with the result of study conducted by Iqbal and co-authors ${ }^{19}$. In their study majority of patients presented with good visual acuity. This difference in presenting visual acuity may be due to severity of ocular trauma. In our study we included patients who required hospital admission. Patients with minor ocular trauma were not included in our study.

Among the limitations of our study is the small sample size. This study may not be true representative of population as patients from high socioeconomic strata were unlikely to come to public hospital. Patients who needed hospital admission were included in our study. This is another limitation. Patients with minor injuries who did not need hospital admission or did not come to hospital were not included in the study.

Nevertheless, our study underscores the frequency and patterns of ocular trauma in particular locality. It will help establish preventive and management strategies to cope with ocular trauma. Future research is needed to study the impact of health education on adaption of safety measures in preventing ocular trauma. Moreover, it will be important to study the anatomical and physiological outcomes of ocular trauma management strategies.

\section{CONCLUSION}

Ocular trauma occurred more commonly in males. Ocular trauma was blunt and occurred in home setting in most of the times. The aetiological agent in most of the eye injuries was metal and wood. Ocular injuries resulted in substantial visual loss at the time of presentation.

\section{Author's Affiliation}

\section{Dr. Muhammad Luqman Ali Bahoo}

Associate Professor and Head of Ophthalmology, Shahida Islam Medical College, Lodhran.

Dr. Ahmad Zeeshan Jamil

Associate Professor of Ophthalmology, Sahiwal Medical College, Sahiwal.

Dr. Beenish Karamat

Resident Medical officer, Department of Radiology, LGH.

\section{Author's Contribution}

Dr. Muhammad Luqman Ali Bahoo

Concept, Study Design, interpretation of data

Dr. Ahmad Zeeshan Jamil

Drafting of article and critical revision for important intellectual content

Dr. Beenish Karamat

Statistical analysis, literature research and proof reading

Conflict of interest: None.

Financial disclosure: None.

\section{REFERENCES}

1. Bahoo MLA, Jamil AZ. Types of ocular surface foreign bodies and their correlation with location in the eye. Pak J Ophthalmol. 2018; 34 (1): 25-9.

2. Jan S, Khan S, Khan MT, et al. Ocular emergencies. JCPSP. 2004; 14: 333-6.

3. Guerra Garcia RA, Garcia D, Martinez FE et al. The Cuban ocular trauma registry. J Clin Exp Ophthalmol. 2013; 4 (2): 276.

4. Negral AD, Thylefors B. The global impact of eye injuries. Ophthalmic Epidemiol. 1998; 5: 143-69.

5. Tsedeke A, Yeshigeta G, Fessehaye A. A 2 year review of ocular trauma in Jimma University specialized hospital. Ethiop J Health Sci. 2009; 19: 67-74.

6. Babar TF, Khan MN, Jan S, et al. Frequency and causes of bilateral ocular trauma. JCPSP. 2007; 17: 679-82.

7. Bahoo MLA, Jamil AZ, Khalid MS. Ocular surface foreign bodies and their association with profession. PJMHS. 2018; 12 (2): 495-8.

8. Khatry SK, Lewis AE, Schein OD, et al. The epidemiology of ocular trauma in rural Nepal. Br J Ophthalmol. 2004; 88: 456-60.

9. Khatry SK, Lewis AE, Schein OD, Thapa MD, Pradhan EK, Katz J. The epidemiology of ocular trauma in rural Nepal. Br J Ophthalmol. 2004; 88: 456-60.

10. Magarakis M, Mundinger GS, Kelamis JA, Dorafshar AH, Bojovic B, Rodriguez ED. Ocular injury, visual impairment and blindness associated with facial fractures: a systematic literature review. Plastic and reconstructive surgery, 2012; 129: 227-33.

11. Bowling, B. Kanski's clinical ophthalmology a systematic approach, 2015; Sydnery: Saunders.

12. Pandita A, Merriman M. Ocular trauma epidemiology: 10-year retrospective study. N Z Med J. 2012; 125: 61-9.

13. Kuhn F, Morris $\mathbf{R}$, Witherspoon $D$, et al. A standardized lassification of ocular trauma. Ophthalmology, 1996; 103: 204-3.

14. Godar ST, Kaini KR, Amatya P, Joshi K, Singh L. Magnitude of ocular trauma in a tertiary care hospital of western Nepal. NJMS. 2013; 2 (2): 140-3. 
15. Sthapit PR, Marasini S, Khoju U, Thapa G, Nepal BP. Ocular Traumain patients presenting to Dhulikhel Hospital. KathmanduUniv Med J 2011; 33: 54-7.

16. Sengupta P, Mazumdar M, Gyatsho J. Epidemiology of ocular trauma cases presenting to a tertiary care hospital in a rural area in West Bengal, India over a period of 2 years. IOSR-JDMS. 2016; 15: 92-7.

17. Hussain M, Moin M, Aasi NA. Epidemiology of Penetrating Trauma. Annals of KEMC (Lahore) 2003;9(2):163-166.
18. Oum BS, Lee JS, Han YS. Clinical features of OcularTrauma in Emergency Department. Korean J Ophthalmol. 2004; 18: 70-8.

19. Iqbal Y, Khan QA, Zia S, Malik A. Frequency and characteristics of ocular trauma in Gilgit, Pakistan. JIIMC. 2016; 11: 157-62.

20. Shaeri M, Moravveji A, Fazel MR, Jeddi FR. Status of ocular trauma in hospitalized patients in Kashan, 2011: As a sample of industrial city. Chin J Traumatol. 2016 Dec. $1 ; 19$ (6): 326-329. 